\title{
PROCESSO EMPREENDEDOR: UM ESTUDO COM MÚSICOS INDEPENDENTES EM VITÓRIA DA CONQUISTA-BA
}

Josilene Pires Matias ${ }^{1}$

Almiralva Ferraz Gomes ${ }^{2}$

Rita De Cássia Oliveira Lima Alves ${ }^{2}$

Weslei Gusmão Piau Santana ${ }^{2}$

\footnotetext{
${ }^{1}$ Universidade Estadual do Sudoeste da Bahia

${ }^{2}$ Universidade Estadual do Sudoeste da Bahia/Departamento de Ciências Sociais Aplicadas (DCSA)
} 


\section{PROCESSO EMPREENDEDOR: UM ESTUDO COM MÚSICOS INDEPENDENTES EM VITÓRIA DA CONQUISTA-BA}

\section{Resumo}

O empreendedorismo é um processo complexo que vai além da geração de novas ideias, pois a gestão do negócio propriamente dito pode assegurar os ganhos e a permanência no mercado. Nesse sentido, este trabalho se propõe a analisar o modo como artistas independentes gerem seus empreendimentos musicais em Vitória da Conquista, Bahia. O presente trabalho é de natureza teórico-empírica e do tipo descritivo-exploratório. Adotando o critério de acessibilidade, onze artistas foram entrevistados através de um roteiro semiestruturado. Os dados coletados receberam tratamento qualitativo. Os resultados mostraram que a gestão está relacionada ao planejamento de curto prazo e restringe-se a construção de projetos para atender as demandas festivas sazonais como o São João e o Carnaval. Os artistas musicais independentes se sentem realizados ao fazerem o que gostam, mas poucos estão contentes com o retorno financeiro da atividade.

Palavras-chave: Ação empreendedora. Empreendedorismo. Música Independente. Músico empreendedor. 


\section{Introdução}

O empreendedorismo é um tema de discussão das ciências sociais há mais de 100 anos, além de objeto de estudo e de ação da Administração enquanto ciência. Alguns avanços sobre o tema, inclusive, tem mudado a forma de estudá-lo. As discussões mais atualizadas questionam o foco desses estudos limitado ao sujeito enquanto ser de características e qualidades extraordinárias. A ação empreendedora proposta por Cramer (2002) e ratificada por Gomes, Lima e Cappelle (2013), posteriormente, tem buscado analisar as ações que compõem o que se denomina empreendedorismo.

Vitória da Conquista, fundada há 177 anos, situada na região Sudoeste da Bahia, possui uma população estimada pelo IBGE (2017) em 348.718. Trata-se de uma cidade em destaque no cenário regional em função, principalmente, da existência de um polo de serviços voltado para educação (superior) e saúde. Ademais, é ainda considerada um polo comercial, pois atende aproximadamente 200 municípios circunvizinhos, inclusive o norte de Minas Gerais. A cidade também é destaque no setor musical ao promover inúmeros espetáculos e, inclusive, sediar o Festival de Inverno (evento que atrai milhares de pessoas de todo o Brasil) para apreciar artista de renome nacional no frio característico da cidade baiana. Ademais, a cidade possui conservatórios musicais gratuitos e privados. Sua vocação para a música é reconhecida pelos talentosos artistas conhecidos nacionalmente Elomar Figueira e Xangai. Segundo o Palco MP3 (2017), há 783 artistas independentes no município. Este dado revela que há um número relevante de empreendimentos musicais.

À luz da ação empreendedora (CRAMER, 2002; GOMES; LIMA; CAPELLE, 2013), o presente trabalho tem o objetivo de analisar o modo que artistas independentes administram seus empreendimentos musicais na terceira maior cidade da Bahia, Vitória da Conquista, conhecendo o processo empreendedor a partir das propostas de Filion (1999), Dornelas (2001) e Baron e Shane (2007). Para tanto, o presente artigo discorre sobre processo empreendedor, apresenta os procedimentos metodológicos e, posteriormente, após contextualizar brevemente o município em seus aspectos culturais e musicais, trata do processo empreendedor e gerencial de empreendimentos musicais independentes em Vitória da Conquista. Por fim, traz suas considerações finais.

\section{Processo Empreendedor}

O empreendedorismo ainda é um tema complexo, objeto de estudo da Economia, da Psicologia e, posteriormente, da Administração. Nas duas primeiras grandes áreas, percebe-se uma grande relevância dada ao sujeito empreendedor, enquanto agente especial, dotado de extraordinariedade. Os estudos mais recentes questionam tal foco e propõe um olhar sobre as ações empreendedoras.

Julien, Marcliesnay e Machado (2010) consideram, inclusive, que a cultura e sua prática vão de encontro às abordagens de duas dimensões: a econômica e a comportamentalista. Eles reconhecem a variabilidade que pode haver entre os países e que isso pode ser relativamente fomentador da plataforma empreendedora. Portanto, indicam que não cabe compreender as vivências empíricas só considerando os métodos simplificados da literatura tradicional, pois

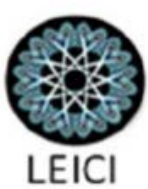


as pessoas estão inseridas em um contexto cultural. Desse modo, é necessário considerar a pluralidade de fatores que influenciam a atividade empreendedora.

O empreendedorismo é um processo composto de três fases, para Baron e Shane (2007). A primeira refere-se à geração de uma ideia para uma nova empresa e/ou reconhecimento de uma oportunidade. Nesse sentido, para Filion (2000b), o reconhecimento de oportunidades depende de uma série de fatores, ou seja, descobrir depende de procurar e para reconhecer é preciso conhecer, considerando que o risco está presente em qualquer empreendimento. Desse modo, é recomendável que o empreendedor esteja habituado com o setor durante alguns anos a fim de desenvolver uma percepção apurada e desafiar as próprias afinidades com a atividade. A experiência prévia no ramo é uma recomendação tanto de Filion (2000b) quanto de Aidar (2007). A segunda fase do processo, para Baron e Shane (2007), é a reunião dos recursos necessários, tais como financeiros, humanos e computacionais, necessários para desenvolver a oportunidade. A terceira é o lançamento do novo empreendimento, administrando o crescimento e colhendo as recompensas.

As fases propostas por Dornelas (2001) não são muito diferentes daquelas defendidas por Baron e Shane (2007), exceto pela inclusão de uma fase (elaboração do plano de negócios). Esta fase é posterior ao reconhecimento de oportunidade, portanto, concebido ainda no início do processo. Considerando as fases sugeridas por Dornelas (2001), o processo empreendedor inicia-se com a identificação e avaliação da oportunidade, que significa considerar a criação e abrangência da oportunidade, os valores percebidos e as reais oportunidades, riscos, retornos da oportunidade, oportunidades versus habilidades, metas pessoais e situação dos competidores (concorrentes).

Sobre o desenvolvimento do plano de negócios, Baron e Shane (2007) não se referem ao estabelecimento de um método e de uma estrutura para se evitar o fracasso como faz Dornelas (2001). Filion (2000a), assim como Dornelas (2001), é um defensor do plano de negócios, tendo em vista que é nessa estruturação que se considera importantes pontos do empreendimento futuro, tais como: necessidades do mercado; observação de tendências; reconhecimento dos pontos fortes e fracos com o reconhecimento de forças e fraquezas do negócio; estabelecimento de visão, objetivos e diretrizes; estabelecimento de metas e avaliação pessoal, além de manutenção do negócio a longo prazo.

\footnotetext{
Antes de tomar qualquer iniciativa, [...] o empreendedor precisa dispor de uma estruturação de pensamento sistêmico e visionário [...], porque é com base nisso que poderá fixar seus objetivos e traçar o caminho para atingi-los - incluindo a previsão dos obstáculos e limites que deverá encontrar. Sem isso, poderá comprometer seus planos e se perder no processo (FILION, 2000a, p.31).
}

Filion (2000a) pondera a necessidade do plano de negócios como tentativa de evitar o comprometimento dos planos e descontrole processual. Gerenciar a empresa criada envolve o estilo de gestão, os fatores críticos de sucesso, a identificação de problemas atuais e potenciais, a implementação de sistema de controle, a profissionalização da gestão e a entrada em novos mercados.

Dornelas (2001) ressalta que a primeira fase (reconhecer oportunidades) é a mais difícil. A terceira fase (reunião dos recursos para a implementação do novo negócio) é a aplicação da segunda (plano de negócios).

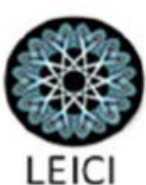


Apesar de gerenciar a empresa parecer ser a parte mais fácil, cada fase do processo empreendedor tem seus desafios e aprendizados. Problemas vão existir e precisarão ser solucionados. O estilo de gestão do empreendedor entra em prática, ao se recrutar adequadamente profissionais para colaborar e implementar ações que visem a minimização dos problemas e identificar o que é prioridade e o que é crítico para o sucesso do empreendimento. Compreende-se, então, que empreender e gerir andam juntos. Sobre a necessidade de gestão, Tavares e Lima (2004) revelam que:

A inovação traz, num primeiro momento, sucesso. Ela nasce de uma busca de oportunidades, criação de oportunidades ou transformação de situações [...] Cria, para a empresa, uma vantagem competitiva. Mas, não se podem esquecer as possibilidades dos concorrentes atuais ou futuros. [...] a falta de reconhecimento de que a gestão é algo que passa por uma construção que a partir do momento em que se cria uma empresa abre-se o espaço para a reflexão sobre a gestão [...] (TAVARES; LIMA, 2004, p. 5-6).

Esta abordagem é muito importante para estabelecer a importância da gestão enquanto última fase do processo empreendedor, pois se torna o elo mais duradouro entre a identificação da oportunidade de negócio e a prática empresarial. Mesmo que a inovação pareça um divisor de águas crucial para o negócio e que produtos inovativos superam os produtos dos competidores, isso não garante uma posição duradoura, visto a facilidade que os concorrentes podem ter em copiar. É fundamental considerar, portanto, o grau de dificuldade de cópia de uma inovação implementada, em produtos e serviços (SALAZAR, 2003 apud TAVARES; LIMA, 2004). Com todos os avanços tecnológicos disponíveis, há muita facilidade para se copiar atualmente.

Diferentemente de Dornelas (2001) e Baron e Shane (2007), Filion (1999) propõe um modelo de gerenciamento alternativo levando em conta o porte das empresas. O modelo proposto por Filion (1999), a ser considerado em pequenas e médias empresas, surgiu a partir do estudo empírico junto a 116 gerentes-proprietários em 19 países, inclusive no Brasil. A visão é fator elementar nesse processo e se refere a uma imagem projetada de uma situação de futuro desejada, um sonho realista e alcançável. O processo visionário de gerenciamento de Filion (1999, p. 10) consiste em cinco dimensões:

(1) visualizar é identificar um interesse num setor de negócios, entender um setor de negócios, detectar uma oportunidade de negócios, imaginar e definir um contexto organizacional e, por fim, planejar (em cima do entendimento de um setor de negócios); (2) criar uma arquitetura de negócios é formular visões complementares, atividades e tarefas gerenciais a serem desempenhadas, estruturar o sistema de atividades e organizá-lo; (3) animar/dar vida é ligar as tarefas aos recursos humanos, recrutar, selecionar e contratar recursos humanos, dirigir os recursos humanos para a realização das visões complementares, comunicar, motivar e liderar; (4) monitorar as realizações e os recursos usados, incluindo o tempo, comparar com as previsões e analisar diferenças, corrigir, ajustar e melhorar é uma outra atribuição; (5) aprender, em qualquer nível, é questionar o que foi feito e como foi feito, considerar as alternativas, buscar elementos de consistência, raciocinar, imaginar e definir e redefinir a visão central e as visões complementares.

Assim sendo, Filion (1999) reúne características de ações alinhadas pela figura
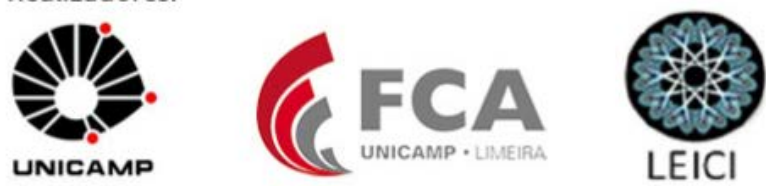
particular do empreendedor, que desempenha um papel "extraordinário” se comparado com o perfil de um gerente. Quanto ao aprender, Filion (1999) enfatiza que as vivências e assimilação do empreendedor sobre o contexto em que o setor está inserido possibilita a obtenção de maiores chances da criação de uma visão de forma precisa. Na estruturação proposta desse processo, o modo aprender está presente tanto no início quanto no final.

Assim como Filion (1999), Paiva Júnior (2004), Gomes, Lima e Cappelle (2013) propõem um gerenciamento advindo da prática empreendedora. Ademais, o reconhecimento dessa prática, muitas vezes, consiste na tentativa e erro. Com isso, o fator aprendizagem surge como elementar. Nem todo empreendedor de pequenas e médias empresas têm a formação para gerir o negócio e Filion (1999) traz um modelo que reflete a prática gerencial nessas organizações, além de reforçar a visão como algo extraordinário e necessário, advindo das vivências no setor no qual é exercido a atividade empreendedora. Lenzi e Santiago (2010, p. 9) também apontam cinco ações que fazem parte do quotidiano do empreendedor em seu negócio:

(1) a ação de preparação é o estágio inicial de planejamento de tudo o que será estabelecido como prioritário; (2) a ação de organização trata da preparação do ambiente de forma que os procedimentos ocorram sem tumulto e com os recursos eficazmente canalizados para os resultados esperados; (3) a ação de avaliação referese à avaliação constante dos resultados para verificar se o caminho escolhido é o mais indicado no momento; (4) a ação de correção ocorre quando há algum problema em uma avaliação adotada constantemente, pois é necessário que se tenha uma ação corretiva de imediato, antes que os resultados negativos sobreponham os positivos e tudo seja perdido; (5) a ação constante pois tais ações sofrem constante e permanentemente um processo de retroalimentação, ou seja, uma nova preparação sempre deve ser pensada e realizada para a reorganização.

Dessa forma, tais modelos puderam subsidiar a pesquisa em evidência, o que possibilitou maior conhecimento acerca da temática.

\section{Procedimentos Metodológicos}

A natureza desta pesquisa é teórica e empírica. Para Demo (2000), toda pesquisa é dedicada a reconstruir teoria, conceitos, ideias, ideologias, polêmicas, tendo em vista, em termos imediatos, que aprimora fundamentos teóricos. Sobre a natureza empírica, fazem parte desse processo as pesquisas dedicadas ao tratamento de face empírica e fatual da realidade, pois produzem e analisam dados, procedendo sempre pela via do controle empírico e fatual (DEMO, 2000).

Além disso, a presente pesquisa é caracterizada como exploratória e descritiva. A pesquisa exploratória faz parte de um conjunto de investigações de pesquisa empírica cujo objetivo é a formulação de questões ou de um problema, com tripla finalidade: (1) desenvolver hipóteses; (2) aumentar a familiaridade do pesquisador com um ambiente, fato ou fenômeno, para a realização de uma pesquisa futura mais precisa ou; (3) modificar e clarificar conceitos. Posterior à exploração, surge o interesse pela descrição do fato/fenômeno. Nesse sentido, a pesquisa descritiva é um levantamento das características exploradas, dos componentes, do fato/fenômeno/problema, de acordo com Santos (1999). A pesquisa
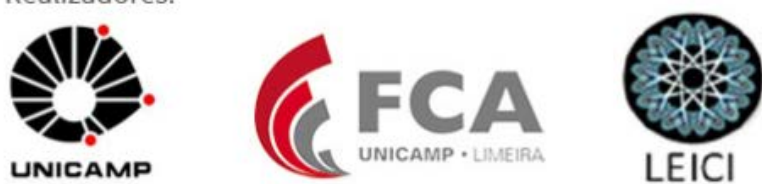
descritiva, para Rampazzo (2011), desenvolve-se mediante a observação, registro, análise e correlação dos fatos ou fenômenos, identificando, inclusive, a frequência com que o fenômeno ocorre. Dentro desse campo, foram escolhidos, portanto, os estudos exploratóriodescritivos combinados, pois têm por objetivo descrever completamente determinados fenômenos como, por exemplo, estudo de um caso para o qual são realizadas análises empíricas e teóricas (LAKATOS; MARCONI, 2001).

A estratégia de pesquisa adotada foi a de estudo de caso. O objeto do estudo de caso pode ser qualquer fato/fenômeno individual, ou um de seus aspectos. Santos (1999) adverte que é necessário que o pesquisador possua grande equilíbrio intelectual, capacidade de observação ("olho clínico") e parcimônia quanto a generalizações, pois se lida com fatos/fenômenos normalmente isolados.

Esta pesquisa utiliza dados obtidos através do portal virtual Palco MP3 que indicou por sua vez a existência de 783 artistas independentes, em Vitória da Conquista, em junho de 2017. Logo, a população conhecida é de 783 artistas. Vale ressaltar que se observou, em alguns casos, mais de um perfil relacionado ao mesmo artista ou banda. Barros e Lehfeld (2000) evidenciam que, geralmente, as pesquisas são realizadas por meio de amostras, pois, nem sempre é possível obter as informações de todos os indivíduos ou elementos que compõem o universo ou a população que se deseja estudar. Conforme Dyniwiez (2009), é necessário que a amostra seja selecionada mediante critérios. A intenção da definição desses critérios é circundar um grupo para que se possa extrair a amostra desejada a pesquisa. Deste modo, esta pesquisa considerou os seguintes critérios de abordagem: (1) Atuação igual ou superior há dois anos; (2) Exercício atual da atividade musical; (3) Disponibilidade para a participação na pesquisa; (4) Concordância com o termo de permissão para divulgação dos dados da pesquisa.

Desse modo, optou-se, assim, por uma amostra não-probabilística. Com isso, onze sujeitos foram entrevistados, adotando-se o critério de acessibilidade. Esse critério é adotado em amostras não-probabilísticas, ou seja, acontece quando os sujeitos são escolhidos para compor a amostra de acordo com a conveniência e facilidade do(a) pesquisador(a) (APPOLINÁRIO, 2011).

O instrumento adotado para a coleta de dados foi a entrevista semiestruturada, pois é um modelo flexível a eventuais perguntas no decorrer da aplicação do roteiro, ou seja, o entrevistador tem a liberdade de extrair mais do seu entrevistado, para além do roteiro (BARROS; LEHFELD, 2000). O modelo do processo empreendedor escolhido para a análise foi o multifacetado que leva em conta a proposta de Filion (1999) e, principalmente de Baron e Shane (2007) e Dornelas (2001).

O tratamento aos dados coletados em campo foi qualitativo. De acordo com Creswell (2010), a pesquisa qualitativa busca captar o significado que os indivíduos ou os grupos atribuem a um problema social.

\section{A Cultura e a Música em Vitória da Conquista: uma breve contextualização}

Desde 1930, Vitória da Conquista já contava com banda filarmônica e banda de baile. Em 1981, passou a contar com ensino musical gratuito através do Conservatório Municipal. Conforme o Currículo Cultural (PMVC, 2009), atualmente, Vitória da Conquista é um dos
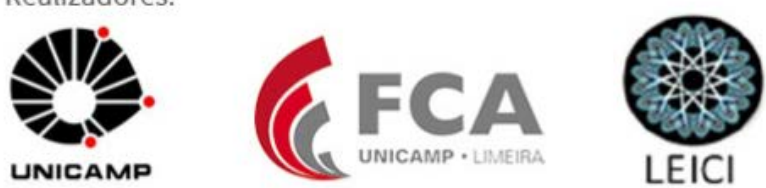
mais importantes centros produtores de cultura na região. O Município aglutina uma tradição cultural intensa, concentrando e polarizando uma região com população acima de 2 milhões de pessoas. É polo também nos campos da arte e cultura com destaque para as figuras do músico Elomar Figueira Mello, o pianista Ricardo Castro, o cineasta Glauber Rocha e o escritor Camilo de Jesus Lima. Para além desses nomes de expressão nacional, Vitória da Conquista é um dos mais importantes centros produtores de cultura do interior da Bahia, com representação em quase todos os campos do fazer artístico e com destaque para as manifestações populares e folclóricas, conforme o Currículo Cultural (PMVC, 2009).

O Currículo Cultural (PMVC, 2009) aponta que há uma variedade de trabalhos culturais no município produzida pelos artistas locais, desde a criatividade oriunda da observação da temática regional até leituras mais universais. O Currículo Cultural (PMVC, 2000, p. 4) indica, também, que Vitória da Conquista é "um celeiro cultural de artistas plásticos, escritores, poetas, atores, cantores, compositores, músicos, coreógrafos, dançarinos, videomakers, vencedores de festivais de artes, que levam o nome de Vitória da Conquista para todas as regiões do país”. Além disso, o traço folclórico marca a história da cidade. Isso fica ainda mais notório em eventos tradicionais que acontecem anualmente como o "Natal da Cidade”, São João e o Terno de Reis. Além do Natal da Cidade e São João, a Mostra Cinema Conquista e o Aniversário da Cidade já fazem parte do calendário cultural conquistense. Outros eventos são promovidos durante o ano, como é o caso das festas típicas que estão sendo revitalizadas nas localidades da zona rural (Festa da Farinha, Festa da Bandeira, entre outras), sempre com o propósito de buscar aproximação e contato maior da cidade com a sua história e com as suas tradições (PMVC, 2009).

\section{Processo Empreendedor e Gerencial de Empreendimentos Musicais Independentes}

Antes de se tratar do processo empreendedor propriamente dito, traçar-se-á um breve perfil dos informantes que participaram da presente pesquisa. A entrevista foi realizada com 11 (onze) artistas musicais de diversos estilos. Dos entrevistados, 9 (nove) foram homens e 2 (duas) mulheres. O nível de escolaridade dos informantes foi de ensino fundamental à pósgraduação (mestrado), sendo que a maioria possui ensino superior. O tempo de atuação artística mínima dos informantes foi de 3 anos e o de atuação máxima igual a 41 anos. Foram adotados nomes fictícios para os entrevistados a fim de manter o sigilo de suas identidades: tais nomes foram eleitos a partir da linearidade alfabética, de modo que o primeiro entrevistado recebeu o "A" em seu nome, primeira letra do alfabeto e o último informante recebeu o "L", conforme décima primeira letra do alfabeto. Seguindo este critério, adotaramse nomes para cada participante da pesquisa.

Conforme os perfis relatados, a maioria dos respondentes desempenha outras atividades em paralelo à música, com exceção de três entrevistados, são eles: Galileu, Ingo e Jade. Ou seja, estes últimos dedicam-se exclusivamente à música. É importante observar que, apesar de a maioria ter seu trabalho desenvolvido por meio de carreira solo, apenas Jade, Enzo e Fábio conseguem exprimir no dia a dia essa modalidade. Eventualmente, artistas multiinstrumentalistas como Ingo, Galileu e até vocalistas como Bob conseguem articular um trabalho sozinho, sendo, então, protagonistas na gravação de seus trabalhos. Efetivamente, atuam cotidianamente como integrantes, inclusive, em mais de uma banda musical.
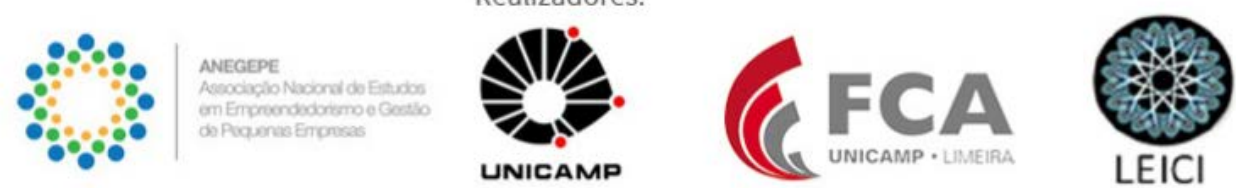
Levando-se em conta que o processo empreendedor inicia-se através da identificação de uma oportunidade (BARON; SHANE, 2007, DORNELAS, 2001) e é advindo de uma visão a partir de uma vivência no setor (FILION, 1999), percebeu-se que os artistas musicais entrevistados foram movidos, inicialmente, pela afinidade pessoal ou pela paixão pela música e, posteriormente, pela identificação de demanda, entre outros fatores. Contudo, o amadurecimento no setor que promove a concepção de uma visão precisa, conforme sugerido por Filion (1999), foi exercido de modo voluntário: tocar e cantar sem remuneração (cachês), na maioria das vezes.

[...] eu só entrei na banda para ajudar um amigo [...] e, aí de repente ele saiu e eu acabei entrando no lugar, [...] não foi 'Ah... Vou montar uma banda hoje.' [...], a música meio que foi entrando aos pouquinhos e fui gostando.[...] Como produtor, eu decidi por não ter um espaço para ensaiar. Esse era o principal problema para uma banda na época quando eu montei. Era muito difícil ter espaço. Então, eu resolvi montar um espaço, foi daí que eu comecei empreender mesmo na música, era mais um hobby essa, tocar pros amigos, tocar em festas sem nem cachê, depois eu comecei a trabalhar, ter o estúdio, precisar ter equipamento, eu comecei alugar o espaço para outras bandas e aí surgiu a ideia de ganhar dinheiro com isso. Depois, veio a ideia de tocar ganhando também, e tal. Mas, ai quando já estava um pouquinho melhor né, no começo nunca é tão bom (André).

André revela que, num primeiro momento, buscou um local apropriado para realizar os ensaios da sua banda em particular. Esta decisão/ação o levou a se dar conta de que essa era uma carência no mercado conquistense. Com isso, vislumbrou a possibilidade de criar um espaço para locação que atendesse essa demanda reprimida. A oportunidade, portanto, foi identificada em decorrência da vivência no setor, conforme defende Filion (1999). Os outros entrevistados também identificaram demanda para a atuação musical. Assim, passaram pela fase inicial sugerida por Filion (1999), que envolve visualização, ao se detectar uma oportunidade de negócio.

O que me levou a empreender foi, principalmente, essa aptidão que Conquista tem, que a nossa cidade tem pra o alternativo que é uma aptidão muito boa de ouvir o novo, de querer ouvir o que tá fora do eixo que a gente chama de eixo mainstreaming que é o, que não toca na rádio, que não tá na novela, Conquista tem uma aptidão para conhecer as bandas mais da cena independente, seja ela de qualquer estado do Brasil. Às vezes, vem banda do Rio Grande do Sul, de Minas Gerais, para tocar aqui e tem público porquê as pessoas daqui conhecem, tem essa aptidão (Bob).

[...] Um trabalho solo mais objetivo só aconteceu em 2007, quando eu decidi gravar um disco solo. É um disco sendo eu o protagonista, porque você acompanha vários artistas, e de repente, você sente a necessidade de ter um trabalho que você protagonize mais, se não você fica sempre como aquele músico que acompanha, que toca certas coisas, etc e tal, mas nunca tem assim, um trabalho propriamente seu, fica mais um trabalho do artista principal que é o foco (Galileu).

O que Galileu sentiu em relação a necessidade de protagonismo, ao gravar um material musical próprio, foi similar ao que Enzo percebeu enquanto estava na Banda Forró 1. Os dois optaram por se expor mais e ter um nome para apresentação ao público. A diferença entre eles

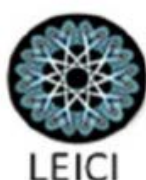


é que Enzo dedica-se à carreira solo com exclusividade, enquanto Galileu, atualmente, ainda acompanha outros empreendimentos musicais. Nesse sentido, é possível que a soma da habilidade com um instrumento e com a voz permita a Enzo carreira solo. Galileu atua em três grupos musicais e produz material gravado como trilhas sonoras, etc. Ambos consideram a questão do nome um fator muito importante junto ao público.

O modelo de Dornelas (2001) que considera o plano de negócios acaba sendo insuficiente para compreender a vivência do processo empreendedor dos artistas musicais independentes abordados, pois não foi identificado a sua realização. Desse modo, Baron e Shane (2007) que não o aborda, se torna o mais próximo da prática desses empreendedores. Para Baron e Shane (2007), após a identificação de oportunidades segue a reunião de recursos. Tal fase aconteceu de maneira gradual no setor musical no município de Vitória da Conquista. À medida que os artistas amadurecem, identificando a qualidade de seus instrumentos e desenvolvendo habilidades com ferramentas mais sofisticadas, buscaram realizar gradualmente as aquisições necessárias. Muitas vezes, o investimento foi pessoal ou proveniente de cachês adquiridos com a atividade musical. Em geral, os custos dos instrumentos foram elevados, conforme Galileu revela no trecho selecionado abaixo.

Em geral, esses instrumentos são muito caros,[...] então, leva tempo para a gente reunir o dinheiro e comprar. Acho que levou, pelo menos, uns cinco anos até eu juntar o dinheiro e comprar os instrumentos. Os da Orquestra foi por via projeto e editais, a aquisição dos instrumentos[...] porque são instrumentos muito caros[...] então, [...] essa verba federal ajuda muito. Nesse sentido, as políticas públicas têm que tá bem afinada pra se conseguir (Galileu).

Galileu comenta sobre a importância da aquisição de instrumentos com o apoio de órgãos públicos, por meio de editais. Homero pontua a dificuldade de aquisição de instrumentos como uma guitarra do modelo fender que custa em torno de 12 mil reais, enquanto seus cachês semanais giram em torno de 100 a 150 reais.

A terceira fase do processo empreendedor, proposta por Baron e Shane (2007), é o lançamento do empreendimento propriamente dito, a administração do seu crescimento, bem como a colheita das recompensas. Para Lenzi e Santiago (2010), a preparação, organização, avaliação e correção devem fazer parte do cotidiano do empreendedor. A preparação, defendida por Lenzi e Santiago (2010) como o estágio inicial do planejamento, é uma atividade que Bob considera difícil junto aos integrantes do empreendimento:

[...] a gente briga muito [...] é nesse ponto que a gente mais diverge [...], tipo ‘ o que que a gente vai fazer daqui pra frente? Primeiro, a gente vai gravar o CD ou a gente vai primeiro fazer show para arrecadar o dinheiro e depois tirar o CD? Ou a gente não faz show nenhum mais, nem barzinho, nada, para poder se concentrar em fazer o nosso CD [...]' Agora já deram a ideia, o baterista deu a ideia de reunir num sítio, ficar uma semana no sítio compondo (Bob).

Este relato mostra o desafio de lidar ora com a produção (indústria criativa), ora com a prestação do serviço. Bob inteira:

[...] a gente planejade uma forma, inesperada, vamos fazer, vamos fazer, e tal, tal, tal... aí a gente planeja, mas não é nada muito, a gente não planeja o planejamento

Organizadores:

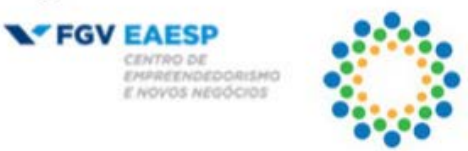

ANEGEPE

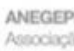

Realizadores:
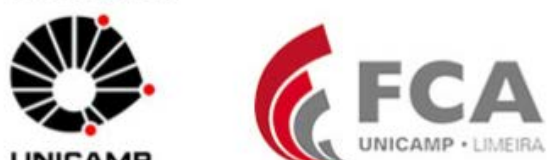

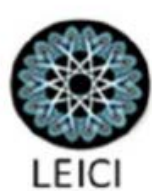


[risos]. Geralmente, a gente termina um ensaio, 'e ai o que a gente vai fazer agora e tal, senta...[...] a gente se organiza muito através de uma ferramenta que é o grupo do facebook [...] a gente, geralmente faz um pauta o que agente precisa, de tal coisa, aí na reunião, a gente tem muita reunião, a gente sempre se reúne e nessas reuniões ficam decididas algumas coisas, é nessas reuniões que rolam essas brigas, mas no final das contas sempre dá certo (Bob).

Há a preocupação com os objetivos e metas. A capacidade de definição do que é prioritário para os próximos períodos é bem clara entre os integrantes da banda de Bob:"Hoje, o nosso momento é de gravação de $\mathrm{CD}$, então, todo recurso é diretamente, [..] a gente não precisa de coordenação, já está pré-decidido, pré-determinado” (Bob).

O planejamento possui dupla face, pois se trata também do planejamento criativo. Galileu pondera que "O planejamento nosso não é um planejamento material! Planejamento criativo é muito difícil [...] O planejamento se dá desde essa inserção estética a você de fato se dedicar a produção disso, e a parte mais objetiva fica com o produtor, que é a questão mais material, datas, etc... De contatos, editais, e as burocracias todas”. Galileu conta com o apoio de dois produtores, um no Rio de Janeiro e outro em São Paulo, o que o ajuda a focar nos aspectos criativos do negócio.

A organização, para Lenzi e Santiago (2010), pretende evitar que os procedimentos ocorram com tumulto e com os recursos eficazmente canalizados para os resultados esperados. Nesse sentido, Bob conta que o baterista é o tesoureiro da banda:

[...] ele organiza toda a questão financeira da gente, a gente tem custo mensal, né? Porquê a gente faz parte de um estúdio [...] estúdio não é barato, e a gente organiza dessa forma assim, tem o tesoureiro, tem as reuniões para saber como a gente vai captar os novos recursos [...] toda questão de recurso captado sempre vai para o caixa da banda,[...] a gente tem um CNPJ de Microempreendedor Individual (MEI) que é de produção cultural, a gente dividiu com o pessoal da banda $\mathrm{X}$, que é uma outra banda muito bem sucedida daqui. Então quando a gente precisa de um edital, pra abrir o edital, a gente precisa de um CNPJ, é assim (Bob).

Já para Dante, a responsabilidade da organização se limita a organizadora do evento: “já é dado a banda toda uma estrutura: de transporte, de hospedagem, né? Quando é para fora, outras cidades, viajando, então, a banda fica livre disso, a única obrigação da banda mesmo é fazer o show acontecer da melhor forma possível” (Dante). Galileu aponta que já conversou com sua produtora sobre fazer um fundo de caixa para investimentos.

[...] eu tiro parte do dinheiro que eu tiro com discos, etc para uma reserva, que às vezes, a gente precisa para produzir algumas coisas, por exemplo, eu tive que investir em filmagens em São Paulo pra gerar Youtube, trabalhos, etc. Então, isso tem um custo e a gente tem que tirar do bolso da gente, e tem que ter um fundo que você reserve pra fazer isso, tem que despachar material para não sei aonde, tem que pagar telefone, [...] então, a gente deduz de cada apresentação, de cada coisa uma quantia, uma quantia mínima[...] (Galileu).

Galileu também relata que os recursos são escassos. Por isso, não há complexidade em seu manuseio. Usam-se tabelas para a remuneração dos sistemas humanos envolvidos e calculam-se os custos de viagem, se for o caso. Lenzi e Santiago (2010) entendem que essas

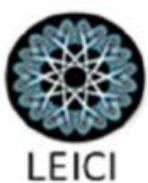


ações são contínuas no dia a dia do empreendedor. Mas, o empreendedorismo musical tem peculiaridades, justamente porque as atividades que dizem respeito a apresentações (shows ao vivo) ocorrem, geralmente, nos fins de semana. No entanto, exigem-se do artista a flexibilidade e a capacidade de adaptação às necessidades do serviço. Para Jade, a organização ocorre de modo sistemático. Se for uma apresentação diurna, num restaurante, prepara-se um repertório com músicas lentas, etc... No caso de formaturas e casamentos, Jade chama dois instrumentistas e eles buscam levar uma apresentação mais dançante, após o ensaio. A atividade de Jade tem relação com a discussão levantada por Filion (1999), ao propor ligar as tarefas às pessoas, ou seja, animar/dar vida.

Os ensaios se tornam cruciais para que a função organização seja efetivada. Contudo, enquanto Galileu ensaia um espetáculo de 3 a 4 horas por dia, ou seja, ensaia duas vezes um espetáculo de duas horas, outros musicistas, principalmente, os que se dedicam a outra atividade se reúnem apenas uma vez por semana a fim de prepararem um show, conforme pode ser observado no trecho selecionado abaixo:

[...] tem que haver um horário onde todos os músicos estão disponíveis. Então, todos têm que ser organizar naquela agenda.[...]Normalmente se usa um ou dois dias na semana para esse encontro regular; para ensaiar ou fazer alguma coisa, uma reunião... entre duas e três horas[...] Não mais que isso. A não ser que toque profissionalmente e goste muito de tá junto um do outro. Mas, é bem difícil.[...] Mas creio que 4 horas por semana dividido em dois períodos é normal, duas horas num dia, duas horas no outro. E tem hora de tocar também que você acaba se reunindo, né? Um show de três horas num barzinho: Você gasta pelo menos quatro horas e meia, em quarenta e cinco minutos antes. E 45 depois montando e desmontando equipamento. Então você tem esse período junto: 4 horas, cinco horas juntos (André).

A necessidade de tempo de ensaio passa muito pela inclusão de músicas novas no repertório. Nesse caso, há encontros e ensaios só para musicar a proposta. Ademais, o tempo depende das habilidades dos instrumentistas e da sua agilidade de assimilação: "Talvez eu tenho que estudar para chegar até aquela música ou posso criar uma coisa mais simples” (André). Embora o ensaio em grupo seja limitado, o aperfeiçoamento pode ocorrer nesse intervalo, conforme André. O estudo a que ele se refere é um aprofundamento particular. Desse modo, verifica-se uma disparidade de tempo entre os ensaios de Galileu e o de André, ou seja, enquanto Galileu investe aproximadamente 20 horas em ensaios, André e suas bandas dispõem no máximo de 4 horas semanais. Então, conclui-se que os ensaios minimizam os riscos de tumultos e de problemas na sonorização do trabalho musical, além de permitirem avaliações. Aliás, a avaliação serve justamente para monitorar se o caminho escolhido é o mais adequado (LENZI; SANTIAGO, 2010). Num sentido mais amplo, Bob afirma que:

São realizadas avaliações, [..] isso é uma coisa que a gente faz espontaneamente, [...] eu diria até que é uma coisa anual, tem uma época assim, que é o início do ano. Toda vez é assim, [...] a gente se reúne no início do ano e fala ' o que que a gente teve no ano passado, o que a gente conquistou?' [...] Eu sou muito contente com o nosso gráfico, de 2014 para 2017 [...] ele é ascendente, porque a gente foi conquistando as coisas e isso é muito legal (Bob).
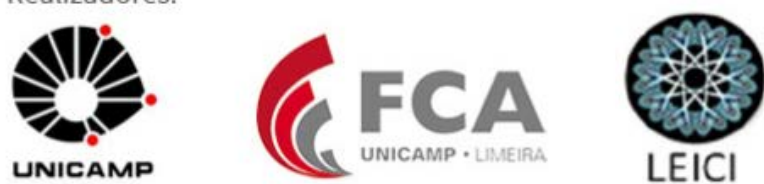
Esta avaliação é o que Filion (1999) chama de monitoramento. Em outros termos, acompanhar o crescimento ascendente do empreendimento, comparando as previsões e analisando as diferenças, nada mais é do que monitorar a atividade.

As correções, penúltimo ponto das ações quotidianas defendidas por Lenzi e Santiago (2010), mostram-se tipicamente úteis nessa atividade, conforme pode ser verificado no depoimento de Jade, ao tratar do cuidado que o grupo tem, em cada apresentação, com a verificação da harmonia de encaixe de volume de voz, de instrumentos, no intervalo das canções de dar um feedback, além da avaliação geral do trabalho. André, nesse processo, busca conhecer o olhar de um agente de confiança sobre o espetáculo. Esse procedimento está de acordo com os pressupostos de Lenzi e Santiago (2010): avaliação e correção possibilita a aprendizagem, sugerida por Filion (1999).

O último ponto é a nova preparação pensada para a reorganização, ou seja, uma continuidade desse ciclo que, de modo indireto, diz respeito ao absorvimento de aprendizado defendido por Filion (1999).

Então, sobre a gestão, a maioria das bandas tem, em suas atividades de retaguarda, o momento em que há pouco ou nenhum contato com os usuários/clientes, a produção criativa, seja de composições ou de arranjos. Por meio dos ensaios com o grupo, tentam prever o resultado das apresentações, além da tentativa de musicar novidades. Em geral, a maioria tem um ou dois encontros de duas horas, durante a semana. No entanto, para artistas que se dedicam com exclusividade a atividade musical, o estudo é diário e os ensaios uma rotina. A dedicação só não é mais afinca porque se deve dispensar alguns cuidados com a saúde para evitar lesões por esforço repetitivo e tendinite. Então, a fase de ensaios seria o que Filion (1999) chama de animar/dar vida, ou seja, delegar as atividades para as pessoas realizarem, se refere a tarefa e as pessoas envolvidas (FILION, 1999).

O planejamento desses empreendimentos é marcado pela pesquisa e pela inspiração. Luiza ressalta que "pesquiso sobre o mercado da música, novas ideias, gosto do público, etc...” Outro ponto é o desenvolvimento dos projetos musicais. Deste modo, se for para atender ao período junino, por exemplo, busca-se montar um repertório específico, ensaiar, inscrever-se em editais para atender a tal demanda. Às vezes, busca-se reunir com outros músicos para atender a necessidade de projetos específicos. Então, apesar do planejamento ser limitado ao curto prazo e ao histórico de eventos tradicionais, como o Carnaval e São João, existe na prática dos músicos. Isso, também, pode ser compreendido como a criação de uma arquitetura de negócio, conforme Filion (1999), ou seja, formulam-se atividades e tarefas gerenciais a serem desempenhadas, estrutura-se o sistema de atividades e o organiza.

Faz parte da terceira fase do processo empreendedor as recompensas. Na prática dos empreendedores musicais, a maior recompensa está ligada à autorrealização. Esta, por sua vez, tem relação com a necessidade de realização proposta por McClelland, na década de 1970. De um modo geral, os ganhos financeiros são pouco satisfatórios, com exceção de Dante, Ingo e Jade. Os trechos selecionados abaixo revelaram tal satisfação, embora com algumas ressalvas:

[...] no início é difícil, muitas vezes, faz até de graça, faz mesmo com a paixão primeiramente, e que acaba também, escola que você acaba fazendo, é tipo um estágio, você faz e doaali seu trabalho, mas ao mesmo tempo a gente tá aprendendo. Aí você faz isso no início e depois que você começa a colher os frutos, é muito bom. Os ganhos dependendo do profissional que você se torna, o nível que você chega, os

\section{Organizadores:}
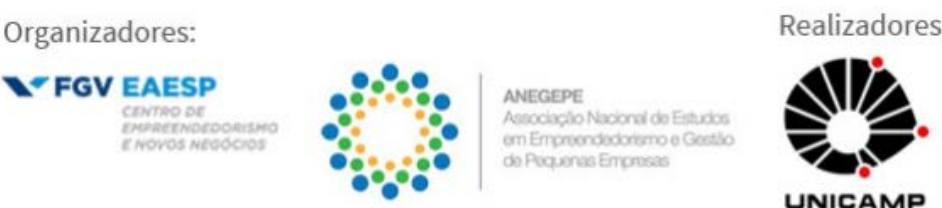
ganhos são excelentes. Estou satisfeito, não tenho do que reclamar. [...] como produtor e como músico, porque se você fica só em uma função automaticamente você vai ficar um pouco limitado, mas se você abrange tanto tocando, exercendo como músico, exercendo como produtor,como arranjador, como compositor, então cada função que vai agregando [...] e aí a gente também vai ganhando mais por isso (Dante).

Hoje, eu vivo bem com a música por ter, graças a Deus, uma agenda cheia, eu tenho trabalhado bastante. Mas, o cachê que cada um oferece pra gente é pouco, [...] então assim, eu tô bem, eu consigo me manter[...], viver de música porque eu tenho tido vários sons durante a semana, aí juntando dá para ir pagando as contas[...] É algo que eu gosto de fazer, eu sinto prazer em fazer isso[...]então eu sou realizada, sim.. eutô feliz sim, com meu trabalho e pretendo seguir ai pra vida toda, chegar a idade de Dona Canô cantando [risos]. (Jade).

No meu caso, eu tenho essas três atividades, eu vou na matemática levando a vida assim tranquilo, é... Consegui fazer alguns investimentos, literalmente na música, mas também, em alguns anos, né?[...] estou satisfeito, mas é a matemática [...] eu ganhei tanto, gasto tanto[...] o gasto, geralmente, a gente tem uma base, né? Faculdade de filho, carro, alimentação... [...] Por exemplo, tem mês que entra que cobre dois meses, é mais ou menos essas contas assim... [...] Mas, eu sou satisfeito, tenho satisfação nesse emprego. [...] Eu sinto realizado, e a maioria das vezes, assim, eu consigo fazer os meus horários também (Ingo).

Os demais entrevistados estão insatisfeitos, do ponto de vista econômico. Contudo, são pessoas que demonstram amar o que fazem. Ou seja, apesar da falta de contentamento com a rentabilidade, estão autorrealizados ao fazerem o que gostam.

[...] eu queria estar mais realizado, eu gostaria de tocar mais, de ser mais reconhecido, de talvez a música me dar um retorno maior para que eu pudesse continuar um pouco mais envolvido com ela. [...] acho que falta algo, todo músico independente quer fazer com que sua música seja conhecida por milhões de pessoas talvez esse seja o ponto, não consegui [rs] (André).

Em recursos mesmo, sou absolutamente insatisfeito, [...], eu já recusei vários trabalhos, [...] por questão de valor [...] E eu sou irredutível quanto a isso, [...] se você começa a fazer trabalhos abaixo do valor que você realmente conquistou, é quando você vai fazer um orçamento pra algum edital, alguns lugares pedem três últimos orçamentos de trabalho que você fez[...] para pagar um valor equivalente,[...] assim faz as prefeituras, certo? Digamos assim, na questão de licitação de artista, daí eles pegam três orçamentos meu lá embaixo, então vão me pagar o que. Eu falei não, aquilo ali eu posso ter feito por amizade, posso ter feito por alguma coisa assim, agora vai comprometer seriamente numa hora de licitação do meu trabalho[...] (Galileu).

André e Galileu partilham de insatisfações similares, pois querem retorno financeiro e, para isso, estão dispostos a produzir mais e desejam tocar mais. Quanto a satisfação de questões econômicas, Galileu demonstrou efervescência ao tratar da sua vocação, assim como Bob, conforme pode ser observado nas falas a seguir:

A todo instante, realizado em tá fazendo o que eu vim pra fazer, mas não realizado

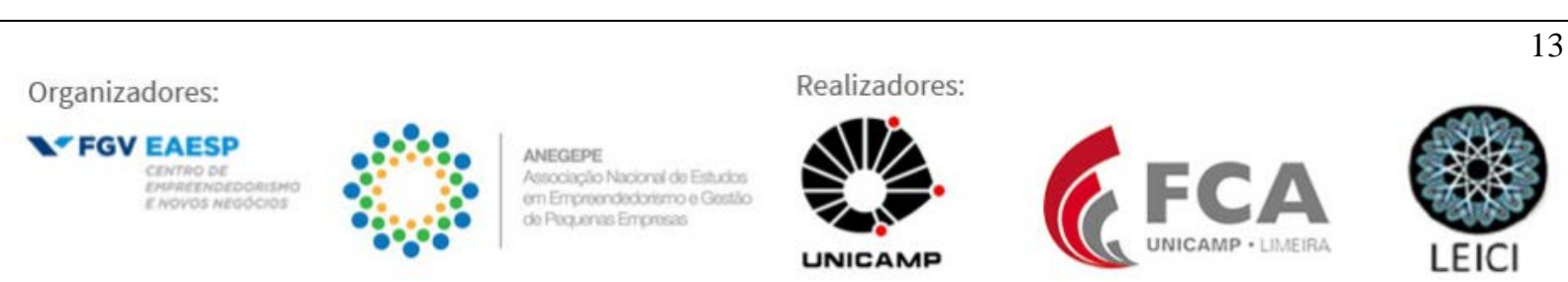


em termos de opção [...] não me sinto realizado, digamos assim economicamente. [...] Mas, o fato é que eu quero realizar muito mais, então, meu momento é pra, digamos assim, cair no mundo, mostrar coisas, trabalhar bem mais, e atuar bem mais, produzir[...] então, não me sinto realizado não, vou deixar isso para falar quando eu tiver bem mais velho[...](Galileu).

Eu nasci para fazer isso, eu não tenho a menor dúvida disso. Eu tenho convicção pessoal de que nasci pra viver de música, [...] Então eu sinceramente, se tivesse 17 anos com [...] consciência de que que eu teria esse projeto, estrutura que eu tenho hoje, eu não teria feito o curso de Direito eu teria feito música, eu teria feito música na UFBA[...] (Bob).

Homero pontua satisfação com ganhos esporadicamente:

[...] no mês passado mês de abril, foi sensacional, eu toquei quase todo final de semana, às vezes, mais de uma vez por dia[...] então assim, aconteceu um bocado de shows e deu um rendimento bacana[...] deu mais da metade do que eu ganho aqui, deu um bom complemento pra mim, sabe? que acaba sendo reinvestido sempre em equipamento[...] não é o que me sustenta não (Homero).

Homero explica que os ganhos com seu trabalho musical, ainda que sejam bons, não passam de uma renda extra. Ademais, refere-se aos baixos cachês dos bares na cidade, assim como o faz também Jade. Contudo, Jade busca atuar de terça a domingo para aumentar sua renda. Homero também explica que há variações na atividade ao longo do ano: "tem mês que é bom, tem mês que é ruim [...] chega São João, você toca mais, chega a época de carnaval, você acaba tocando mais" (Homero). Desse modo, a sazonalidade impacta positiva e negativamente. $\mathrm{O}$ impacto positivo diz respeito ao aumento dos rendimentos em um determinado período. Já os impactos negativos tratam da escassez de espetáculos em tantos outros períodos. Homero conclui que "ao contrário de bares, casamento paga bem”. Ou seja, as pessoas físicas oferecem rendimentos mais satisfatórios, enquanto as empresas, donos de bares, pagam cachês muito baixos.

Fábio e Homero referem-se à satisfação pessoal oriunda do contentamento gerado pela euforia do público, como pode ser observado nos trechos a seguir:

[...] como a gente faz o que a gente gosta, mesmo ganhando mal, , a gente curte. Quando acaba um show, e a gente desce do palco, tá todo mundo elogiando, [...], isso lhe deixa bem, feliz, e me realiza de certa forma.[...] Mas, a realização vem por satisfação, né? A gente toca e gosta de tocar e, por enquanto que está tocando fica satisfeito, né? Isso é uma realização pra mim (Homero).

Os ganhos atuais é ver o público feliz, gostando da música. Esses são os ganhos atuais[...]outro dia mesmo tava fazendo show no Glauber Rocha e o pessoal aplaudiu, gritavam meu nome, então, isso para mim é gratificante demais[...],é um trabalho que é gratificante que eu faço isso com amor, o amor a cultura do Forró, eu gosto, isso para mim é um prazer. [...]Eu me sinto realizado, [...], o que eu mais queria era dominar uma sanfona dessa, e eu consegui tocar ela e cantar, eu consigo. Então, isso pra mim já foi um realizar mesmo. Ganhar um prêmio com essa sanfona [...] (Fábio). 
Fábio se mostra muito feliz em ter alcançado algumas realizações profissionais, como conseguir manusear um instrumento difícil e, ao mesmo tempo, cantar, além de ocupar espaços públicos considerados importantes no município e obter o reconhecimento do público.

\section{Considerações Finais}

Esse trabalho teve o objetivo de analisar o modo que artistas independentes administram seus empreendimentos musicais, no contexto empreendedor em que atuam, considerando as suas motivações para começar o negócio.

Os motivos para o empreendedorismo musical relatados pelos entrevistados estão ligados a percepção da vocação e a aptidão do município para a aceitação do que é alternativo. De forma despretensiosa, os agentes sociais desse fenômeno foram movidos pela afinidade artística. E, à medida que se capacitaram através do aprimoramento da técnica, sentiram-se seguros e preparados para começar a fazer negócios com a música e cobrar cachês para apresentações.

A gestão empreendedora das bandas musicais tem se restringido ao domínio de projetos. Deste modo, se for para atender ao período junino, por exemplo, busca-se montar um repertório específico, ensaiar, inscrever-se em editais para atender a tal demanda. Às vezes, busca-se a associação com outros músicos para atender a necessidade de projetos específicos. Nesse setor, há o desafio peculiar de lidar ora com a produção (indústria criativa), ora com a prestação do serviço, inclusive, verificou-se uma certa preocupação com a definição de objetivos e metas. Ademais, o planejamento possui dupla face, pois se trata também do planejamento criativo.

Foi possível detectar, também, que as atividades do músico independente no município são marcadas pela dualidade, ou seja, esses agentes tentam, na maioria das vezes, conciliar a vida artística com o desempenho em outra atividade profissional. São multitarefados até mesmo na atuação musical em si. Sendo assim, desenvolvem, em paralelo, atuação em mais de um empreendimento musical e/ou também atuam como produtores. Desse modo, o contexto em que o músico conquistense atua é desafiante, pois há grandes chances de conflitos ou mesmo tumultos entre as demandas pessoais e profissionais. Em geral, os artistas musicais independentes se sentem realizados ao fazerem o que gostam, mas poucos estão contentes com o retorno financeiro da atividade.

No que se refere às limitações, este estudo se restringiu a técnica de pesquisa qualitativa, sendo o perfil da categoria restrito a um pequeno grupo de músicos. Recomendase para posteriores pesquisas a realização de um levantamento quantitativo no município, a fim de conhecer a situação dos empreendimentos musicais conquistenses. Além disso, poderse-ia realizar um estudo voltado para a administração das artes, especificamente musical, voltada para as esferas regional, estadual ou mesmo nacional a fim de compreender os fenômenos do empreendedorismo musical minuciosamente no Brasil.

\section{Referências}

AIDAR, Marcelo Marinho. Empreendedorismo. São Paulo: Thomson Learning, 2007. 
APPOLINÁRIO, Fabio. Metodologia da Ciência. São Paulo: Cengage Learning, 2011.

BARON, Robert A; SHANE, Scott A. Empreendedorismo: Uma visão do processo. São Paulo: Cengage Learning, 2007.

BARROS, Aidil Jesus da Silveira; LEHFELD, Neide Aparecida de Souza. Fundamentos de Metodologia Científica. 2 ed. São Paulo: Makron Books, 2000.

CRAMER, Luciana. Representações sociais sobre a ação empreendedora. 2002. 81 p. Dissertação (Mestrado em Administração). Universidade Federal de Lavras. Lavras, 2002.

CRESWELL, J. W. W. Projeto de pesquisa: métodos qualitativo, quantitativo e misto. 2. ed. Porto Alegre: Bookman, 2010.

DEMO, Pedro. Metodologia do conhecimento científico. São Paulo: Atlas, 2000.

DORNELAS, José Carlos Assis. Empreendedorismo. Rio de Janeiro: Elsevier, 2001.

DYNIWIEZ, Ana Maria. Metodologia de pesquisa em saúde para iniciantes. 2. ed.

FILION, L. J. Diferenças entre sistemas gerenciais de empreendedores e operadores de pequenos negócios. RAE, São Paulo, v. 39, n. 4, p. 6-20, out./dez. 1999.

Oportunidades de negócio. In: FILION, L. J.; DOLABELA, F. Boa idéia! e agora?

São Paulo: Cultura, 2000a.

Aprender a empreender. In: FILION, L. J.; DOLABELA, F. Boa idéia! e agora?

São Paulo: Cultura, 2000b.

GIL, A. C. Como elaborar Projetos de Pesquisa. 3. ed. São Paulo: Atlas, 1996.

GOMES, Almiralva Ferraz; LIMA, Juvêncio Braga de; CAPELLE, Mônica Carvalho Alves. Do empreendedorismo a noção de ações empreendedoras: reflexões teóricas. Revista Alcance, Itajaí, v. 20, n. 2, p. 203-220, 2013.

IBGE. População. Documento online. Disponível em: <https://cidades. ibge.gov.br/brasil/ba/vitoria-da-conquista/panorama> Acessado em : 13 mar. 2018.

JULIEN, Pierre-André; MARCHESNAY, Michel; MACHADO, Hilka Vier. Interdisciplinaridade da pesquisa em empreendedorismo e em PME: Por uma teoria empreendedora que contemple diferenças culturais. Revista Gestão e Planejamento, Salvador, v.11, n. 2, 2010.

LAKATOS, Eva Maria; MARCONI, Marina Andrade. Fundamentos da Metodologia científica. 4 ed. São Paulo; Atlas, 2001.

LENZI, Fernando César; SANTIAGO, Nelson Marcelo. Ação empreendedora. São Paulo: Editora Gente, 2010.

PAIVA JÚNIOR, F. G. O empreendedorismo na ação de empreender: uma análise sob o enfoque da fenomenologia sociológica de Alfred Schütz. 2004. 369 p. Tese (Doutorado em Administração) - Universidade Federal de Minas Gerais, Belo Horizonte, 2004.

PMVC. Currículo Cultural. Vitória da Conquista: PMVC/Secretaria de Cultura, Turismo, Esporte e Lazer, 2009. 16p. (Mimeo).

RAMPAZZO, Lino. Metodologia científica: para alunos do curso de administração e pósgraduação. São Paulo: Edições Loyola, 6. ed., 2011.

SANTOS, Antônio Raimundo dos. Metodologia científica. Rio de Janeiro: DP\&A Ed., 1999. TAVARES, Tatiane Silva; LIMA, Juvêncio Braga de. Empreendedorismo, empreendedores e ação empreendedora. In: ENCONTRO ANUAL DA ANPAD, 2004, Rio de Janeiro. Anais... Rio de Janeiro, 2004.

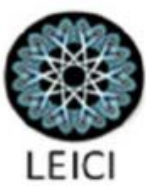

